\title{
BOATE KISS E A RESSIGNIFICAÇÃO DO COTI- DIANO DE UMA SOBREVIVENTE
}

\author{
JULIANA MAIA BORGES \\ CENTRO UNIVERSITÁRIO METODISTA \\ PORTO ALEGRE, RIO GRANDE DO SUL, BRASIL \\ JUMAIABORGES@YAHOO.COM.BR \\ ANDREISI CARBONE ANVERSA \\ UNIVERSIDADE FEDERAL DE SANTA MARIA \\ SANTA MARIA, RIO GRANDE DO SUL, BRASIL \\ ANDREISIANVERSA@HOTMAIL.COM \\ MARLIS MOROSINI POLIDORI \\ CENTRO UNIVERSITÁRIO METODISTA \\ PORTO ALEGRE, RIO GRANDE DO SUL, BRASIL \\ MARLISPOLIDORI@GMAIL.COM
}




\section{BOATE KISS E A RESSIGNIFICAÇÃO DO COTIDIANO DE UMA SO- BREVIVENTE}

Resumo: Este estudo aborda o caso "Boate Kiss", incêndio ocorrido em 27 de janeiro de 2013, com o objetivo de discutir a ressignificação do cotidiano de uma sobrevivente e as contribuições do cuidado em Terapia Ocupacional diante da complexidade deste campo.

Palavras-chave: Atividades cotidianas; Resiliência psicológica; Terapia Ocupacional

\section{BOATE KISS Y LA RESIGNIFICACIÓN DEL COTIDIANO DE UNA SO- BREVIVENCIA}

Resumen: Este estudio aborda el caso "Boate Kiss", incendio que ocurrió el 27 de enero del 2013, tener como objetivo discutir las marcas de la tragedia en el cotidiano de una sobreviviente y las contribuciones del cuidado en Terapia Ocupacional frente la complejidad del área.

Palabras clave: Actividades cotidianas; Resiliencia Psicológica; Terapia Ocupacional

\section{KISS NIGHTCLUB CASE AND RESIGNIFICATION OF A SURVIVOR'S EVERYDAY}

Abstract: This study addresses the "Kiss nightclub fire" occurred on January 27th, 2013, with the main objective is the discussion regarding the marks of tragedy in the daily life of a survivor and contributions Occupational Therapy care in front of the complexity of the whole scene.

Keywords: Activities of daily living; Occupational Therapy; Psychological Resilience 


\section{INTRODUÇÃO}

Era madrugada de domingo, 27 de janeiro de 2013, quando o incêndio teve início, na Boate Kiss, aproximadamente às 2h3omin, após ser aceso um sinalizador por um dos integrantes da banda que lá se apresentava (RORATTO, 2013). É possível que tragédias como esta aconteçam por uma sucessão de erros, pois, infelizmente, incêndios muito parecidos com o da Boate Kiss, já sucederam no Brasil e também no exterior.

Têm-se alguns exemplos, com grande semelhança, nos Estados Unidos da América (EUA) e na Argentina, com um número expressivo de vítimas fatais e, ainda, um grande número de sobreviventes.

Nestas ocasiões, os indivíduos acabaram por ter, em um determinado período, suas rotinas modificadas. O "Caso Boate Kiss" comoveu não só a cidade de Santa Maria, como também o mundo, devido ao tamanho da tragédia; talvez, uma das maiores da história da humanidade em ambientes fechados (ESTADO, 2013).

Além dos mortos, centenas de indivíduos sofreram lesões corporais, sendo que alguns permaneceram por grandes períodos internados em hospitais, face à gravidade dos ferimentos e à toxidade da fumaça que inalaram. Nesse contexto, sabe-se que sobreviventes sofreram rupturas em seus cotidianos, necessitando de cuidado e de um olhar diferenciado.

A vida cotidiana do sujeito se revela no entroncamento da realidade exterior e da realidade psíquica, na rede de suas relações sociais, nas atividades costumeiras de autocuidado e automanutenção, nas manifestações de solidariedade (GALHEIGO, 2003). Nesse sentido, uma tragédia, como o "Caso Boate Kiss", afeta esta "produção" de ser e fazer. Segundo Finger (1986), a Terapia Ocupacional é a ciência que estuda a atividade humana e do fazer humano e a utiliza como recurso terapêutico para prevenir e tratar dificuldades físicas e/ou psicossociais que interfiram no desenvolvimento e na independência do cliente em relação às atividades de vida diária, trabaIho e lazer.

Na realidade, a vida ocupacional é composta por todas as atividades que se realiza no dia a dia, desde o levantar pela manhã até a noite com o encerramento da rotina. Essas atividades fazem parte do cotidiano e variam de pessoa para pessoa, de acordo com as condições individuais e socioculturais da vida de cada um.

Apreender o cotidiano implica em entender como se dá a relação su- 
jeito-cotidiano-história-sociedade. Dessa forma, trabalhar com histórias de vida, narrativas e biografias, de acordo com Francisco (2001), permite ao sujeito recontar sua própria história, ressignificar seu cotidiano e se reconhecer como fazedor de sua história e da história do mundo.

O fazer do ser humano, muitas vezes, necessita ser ressignificado, de modo que, o sujeito seja ator de seu processo de transformação. Isto é, após um evento inesperado, o indivíduo apropria-se dos acontecimentos e, diante de seu mundo relacional, busca resgatar a significação para aquilo que vive (ou viverá) diariamente (FRANCISCO, 2001).

Nesse sentido, o presente estudo, aborda a ressignificação da vida de uma jovem envolvida no "Caso Boate Kiss", a qual passou por processos como os apresentados nessa contextualização. Assim, essa pesquisa tem como objetivos a compreensão das marcas que a tragédia deixou no cotidiano desta sobrevivente e as contribuições do cuidado em Terapia Ocupacional diante da complexidade deste campo.

\section{PROCEDIMENTOS METODOLÓGICOS}

Este estudo é parte de uma dissertação de mestrado intitulada "Ressignificação do cotidiano de uma sobrevivente da Boate Kiss: um estudo de caso" e caracterizou-se como uma pesquisa qualitativa, que abordou questões particulares, com conteúdos subjetivos, os quais não podem ser quantificados. Este tipo de pesquisa envolve um universo de significados, crenças, valores, atitudes, motivos e aspirações equivalentes a um lugar mais profundo das vontades, processos e fenômenos que não podem ser limitados a processos operacionais (MINAYO, 1994).

A pesquisa em questão desenvolveu um estudo de caso com um indivíduo sobrevivente do evento denominado de "Caso Boate Kiss". Este estudo baseou-se em técnica de entrevista semiestruturada, onde o entrevistador teve a possibilidade de comentar sobre o tema proposto. O período de coleta de dados deu-se entre agosto e setembro de 2016.

O participante da pesquisa era um sujeito de 22 anos, do sexo feminino, estudante, nascida no estado do RS, vítima do incêndio na Boate Kiss, que esteve hospitalizada por 78 dias, nos quais 15 dias encontrou-se em estado comatoso em razão das queimaduras internas e externas (18\% da área corporal, principalmente membros superiores) e ainda, por ter sofrido uma amputação transtibial, também em função do acidente. 
Foram realizadas duas entrevistas, conforme disponibilidade da entrevistada. As entrevistas foram realizadas em ambiente agradável e tranquilo, sem barulhos e objetos que pudessem interferir na atenção do sujeito, permitindo que estivesse à vontade para expor a sua história e sentimentos. Foram realizadas gravações das sessões em áudio e após, as informações foram transcritas e analisadas, por meio da análise de conteúdo. Seguiram-se as proposições de categorização descritas por Bardin (2006), discutindo sobre as situações de maior impacto relatadas pelo sujeito da pesquisa em suas entrevistas. Neste intuito entrelaçam-se autores que trabalham com essa temática, juntamente com as falas da entrevistada.

Este estudo foi aprovado pelo Comitê de Ética em Pesquisa do Centro Universitário metodista IPA sob o número 1.502.996 de 17/04/2016.

\section{RESULTADOS E DISCUSSÃO}

A seguir, apresentam-se os dados organizados em distintas categorias, elencadas a partir do tratamento das informações obtidas junto à entrevistada, a saber: (1) Fé e espiritualidade; (2) O corpo e o olhar do outro; (3) Mudanças no cotidiano e; (4) Terapia Ocupacional e o cuidado.

1. Fé e espiritualidade

Em uma situação complexa, como a apresentada neste estudo, entende-se a necessidade de trazer assuntos subjetivos, transcendentes, únicos e de muita relevância, como a fé e a espiritualidade, elementos descritos pela participante da pesquisa como fundamentais para a sua recuperação, reabilitação e, ainda, para auxílio de seus familiares.

A fé e a espiritualidade são alocadas, nas falas da participante, como questões centrais em sua recuperação, sendo citadas até mesmo antes de sua família. Por esta razão, estas temáticas apresentaram-se como uma das principais categorias estruturantes na interpretação dos dados da pesquisa. Além disso, os aspectos espiritualistas podem mobilizar energias positivas e melhorar a qualidade de vida das pessoas. Segue a abordagem da participante sobre o assunto:

mais detalhadas:

Deus, minha fé, minha família, amigos e faculdade foram minha fortaleza para que eu pudesse retomar e ter bastante força. 
Corroborando com esta ideia, Pessini (2007) define espiritualidade como o que consente que uma pessoa vivencie um sentido transcendente na vida, tratando-se de uma construção que envolve conceitos como os de fé e/ou sentido. A percepção, os valores emocionais e interpretações relativas aos eventos experimentados não têm uma contraparte única correspondente aos eventos físicos.

As pessoas que sofreram traumas, frequentemente, perdem, por algum tempo, a estabilidade em conduzir o dia a dia e podem, assim, esmorecer diante da motivação para viver. Solidão, vazio, desesperança e desamparo são palavras utilizadas por indivíduos traumatizados, para exprimirem seu estado emocional.

Guerrero et al. (2010) ponderam que a fé em Deus é um sentimento enraizado na nossa cultura e tão necessária quanto outros modos de enfrentamento, mostrando que a espiritualidade apresenta um lugar de destaque na vida das pessoas. No caso em estudo, a entrevistada revela que:

[...] pela minha fé! [...] foi daí que eu tirei forças pra sair da situação que eu me encontrava.

Em meio a tamanha complexidade da situação experienciada, faz-se necessária a busca de alternativas para a vivência saudável do luto, como pode-se observar na fala da entrevistada. A fé, por sua vez, apresenta-se como ferramenta para a aceitação e ajuda nas situações de perdas. Assim, é importante compreender a fé como condição confortante e capaz de oferecer respostas para nossas maiores aflições e ansiedades.

Harold e Koenig (2005) relatam que a religião não é vital apenas para a identidade de muitas pessoas, mas ela é também usada para lidar com situações difíceis da vida - especialmente doenças. Com isso, o uso das crenças - ou práticas religiosas - auxiliam na redução do estresse emocional causado por perdas ou mudanças, como as ocorridas com o caso em questão.

Acredito que voltar ao meu estado "normal”, eu não tenha voltado $100 \%$, porque como disse foi difícil aceitar tudo que aconteceu, mas, através da minha fé, também da ajuda da minha família [...] por acreditarem que eu ia dar a volta por cima. Paciência e fé em Deus! A fé em Deus é a mais importante de todas.

Nessa perspectiva, as práticas espiritualistas exercem um papel ativo no desenvolvimento de mecanismos de superação psicológica (PERES; MER- 
CANTE; NASELLO, 2005). Isto é, as pessoas mais espiritualizadas são mobilizadas a reduzir a ansiedade, aumentar suas esperanças ou o senso de controle. Esta crença pode manter a esperança viva e evitar que desistam de viver. Pessoas hospitalizadas que acreditam em alguma religião melhoraram mais rapidamente do que aquelas que não acreditam (HAROLD; KOENIG, 2005). A respeito da temática, segue excertos do relato da sobrevivente.

\begin{abstract}
A gente tem que ter paciência e fé em Deus para superar os obstáculos e até os limites, porque tipo, não é fácil ficar um bom tempo dentro de um hospital até ficar bem. Poder refletir e poder repensar muita coisa, no caso, nas nossas vidas, poder evoluir, não só mentalmente como espiritualmente, e aos poucos aceitar tudo que aconteceu.
\end{abstract}

Percebe-se que a entrevistada traz a fé e a espiritualidade (destaques desta categoria) em muitos relatos. Ainda, entrelaçando-as com o processo de aceitabilidade da sua situação e de suas perdas, bem como com a importância da resiliência. Essas temáticas se configuram como pilares de sustentação em momentos de dificuldades, principalmente quando se luta pela sobrevivência em meio a uma situação onde muitos já haviam perdido a vida. Desse modo, a fé e a espiritualidade serviram como base para ressignificação de seu cotidiano.

\title{
2. O corpo e o olhar do outro
}

Outro aspecto relevante, mencionado pela entrevistada, foram as alterações corporais, ocasionadas pela tragédia. Temática que traz muitas reflexões; pois, tratando-se de uma jovem, que até seus dezenove anos apresentava um corpo "normal" e, atualmente, se percebe com muitas cicatrizes, marcas (não somente externas) e ainda, questionamentos.

A imagem do corpo humano é, para Assis, Sória e Assis (2012), a figuração de nosso corpo, formada em nossa mente, ou seja, o modo pelo qual o corpo se apresenta para nós. O corpo e a imagem corporal fazem necessariamente parte de qualquer experiência vital do sujeito com o mundo. Para o sujeito do estudo, seu corpo sofreu muitas alterações, gerando dificuldades em se perceber nesse "novo" corpo.

Porque a minha imagem corporal ficou muito afetada, eu pude me olhar no espelho, consegui me olhar no espelho, só em março, porque antes eu não queria ver do jeito que eu fiquei. Como que o 
outro ia me ver? Eu chorei por muito tempo [...].

Ressalta-se que algumas pessoas percebem o corpo como instrumento que deve ser perfeito enquanto que para outras, o corpo deve estar simplesmente em boa saúde física e mental para gerar o bem-estar. Assim, é preciso protegê-lo de todo o excesso. A imagem da perfeição pode se encontrar subjacente a essa conduta. E, principalmente, nos dias atuais, o menor descontentamento com relação a alguma parte do corpo pode torná-lo objeto de retificações, tornando-o assim, objeto das várias mudanças ditadas pela moda (CARRETEIRO, 2005).

Outro aspecto a ser analisado refere-se ao fato que pode existir uma relação entre o ser mulher, a sua feminilidade e a visão do seu corpo, que pode influenciar nas questões de autoestima e nos próprios relacionamentos futuros. O sujeito que apresenta as modificações em seu corpo poderá pensar e "se cobrar" por não ter o corpo anterior ao acidente, caminho, em algumas situações, longo até uma aceitação completa.

Assis, Sória e Assis (2012) confirmam esta ideia quando trazem que a mulher atribui um valor negativo às marcas e cicatrizes sentindo-se, em alguns momentos, inconformada diante da situação. Ademais, manifesta a preocupação com a sua aparência no que diz respeito à representação das sequelas na imagem do corpo. Quanto à esta situação a entrevistada relata:

Fiquei com muito medo, na verdade, de me relacionar. Mas, acredito que isso vai passar [...] com as coisas que aconteceram eu fui amadurecendo. E aí penso, hoje em dia, eu penso que não é a parte estética corporal que define uma pessoa, né? Então, acredito que com o tempo vou melhorando, vou conseguir usar uma roupa curta, sair sem malha [...].

Neste sentido, as cicatrizes e marcas no corpo da entrevistada, como as queimaduras e a amputação transtibial, sofridas com o incêndio na Boate Kiss, deixaram inúmeras sequelas. Em razão da amputação, sua rotina esteve também com grandes alterações, pois necessitou desde o uso de cadeira de rodas, andador e muletas até o treino de marcha e adaptação da prótese definitiva. Frente a essa situação, a entrevistada aborda as dificuldades passadas em decorrência da amputação, mas também relata a superação e contentamento em poder voltar a caminhar.

Eu precisei de ajuda, então fui me preparando psicologicamente 
para "pôr" a prótese. Então, a tão esperada data de poder voltar a caminhar, foi tão esperada e desejada! Com a força de vontade, no primeiro dia que fui fazer [...] experimentar a prótese, por que eu poderia voltar sem ela, né? Eu saí caminhando de dentro da clínica. Mas os primeiros meses foram bem doloridos, a reabilitação [...] o "encaixe" machucava bastante o coto, a luva de silicone também. Pois "eles" eram corpos novos querendo se adaptar ao meu.

Quando a entrevistada relata o desejo em poder caminhar novamente, observa-se que a possibilidade de protetização adquire um caráter bastante singular, uma vez que reconstrói o corpo de forma que o sujeito apropria-se dele novamente, podendo assim, voltar a ser visto como alguém "saudável" (PAIVA, GOELLNER, 2008). Além disso, dentre as marcas que a tragédia trouxe para a vida dessa jovem, tem-se as queimaduras.

A lesão por queimadura é reconhecida como um dos traumatismos que mais incapacitam e desfiguram sua vítima, prolongando o período de cuidado (ASSIS; SÓRIA; ASSIS, 2012). Essa lesão está entre os traumas mais graves, pois, além dos problemas físicos que podem levar a pessoa à morte, também causa desordens psicológicas e sociais. Em sua maioria, as sequelas psicológicas destroem a autoestima, deixando os sujeitos mais suscetíveis a: depressão, fobia, tendência ao suicídio, consumo e abuso de álcool e drogas e o estresse pós-traumático.

Desta maneira, as mulheres que sofrem lesão corporal não apresentam apenas uma marca física, mas também uma mudança na sua autoimagem, assim como, ter que passar por um processo de adaptação de seu corpo, tal como este se apresenta para ela e para o mundo. A respeito desse assunto, segue o relato da entrevistada:

Queimei 18\% do corpo, eu tinha muitas incertezas, quando eu me vi, me achei muito "horrível” no início foi bem difícil né, porque eu não queria aceitar o que aconteceu, chorei uns quantos meses porque achei que minha vida tinha acabado ali né? Então [...] posso dizer que ainda é um pouco difícil, porque as vezes eu penso o porque eu fiquei assim?

Para Bessa, Souza e Rosa (2011), as cicatrizes da queimadura expressam-se não só na pele, mas também na personalidade, sexualidade, autoimagem, humor, atividade laboral e também na execução das atividades que envolvem arrumar o cabelo, tomar banho, preparar refeições, usar transporte público ou privado, entre outras. E com isso, aparecem os questionamentos 
em relação ao olhar e a opinião alheia. Essa informação é contemplada pela fala da entrevistada:

\begin{abstract}
E aí, eu pensava o que eu ia fazer a partir dali? Como as pessoas iam me olhar? Será que ia ser com "pena"? Ainda tem e vai ter por muito tempo o olhar do outro, que é um olhar de curiosidade, que não é um olhar que seja um olhar ruim, um olhar de pena! É um olhar de curiosidade! Como se passasse outra pessoa na rua, alguma pessoa na rua com essas sequelas e a gente olha também, entendeu? É uma coisa que é [...] as pessoas acham "anormal", não é uma coisa que se vê todos os dias né?
\end{abstract}

Nesse contexto, é possível refletir sobre questões abordadas por Goffman (1988), em se tratando de estigma. Isso porque as consequências do "Caso Boate Kiss" marcaram a vida da entrevistada de maneira significativa, alterando a autoimagem, autoestima, e determinando o afastamento, mesmo que momentâneo, do ambiente e do contato familiar e social.

Nessa perspectiva, salienta-se que, possivelmente, as marcas corporais continuarão a remeter aos momentos da tragédia e a despertar os olhares dos outros. Mas, é necessário um olhar que vá além dessas marcas, que compreenda que as angústias e cicatrizes ultrapassam as sequelas físicas. É preciso um olhar que acolha uma história, que veja o sujeito com suas vontades, habilidades e sentimentos.

\title{
3. Mudanças no cotidiano
}

As pessoas realizam suas atividades rotineiras sem perceberem a complexidade que elas apresentam. Muitas vezes, isso só é compreendido quando expostas a situações diferenciadas, como a de uma patologia, hospitalização, entre outras. Nesse contexto, o sujeito da pesquisa apresentou alterações em seu cotidiano quando este envolveu dias de hospitalização; outros tantos dias de recuperação em seu domicílio, um grande período de reabilitação que se abrange até os dias atuais e a aprendizagem e a dificuldade em conviver com a perda de amigas que estavam no incêndio da boate Kiss.

Assim, percebe-se que seu cotidiano esteve alterado, modificado, necessitando ressignificação, como um novo aprendizado, tanto para a entrevistada quanto para seus familiares e amigos. Ilustrando o exposto, apresenta-se uma fala da entrevistada: 
No começo foi muito difícil né? Quando acordei na CTI, e achei que minha vida tinha acabado, tinha dezenove anos, bonita, festeira. Foram meses de um recomeço intenso, porque eu voltei pro meu cotidiano e ele mudou bastante. Claro que, muitas vezes, eu pensava em desistir e me perguntava porque aquilo tinha acontecido comigo. Mas, comecei a ver a vida de outra maneira, a dar valor a muita coisa que eu não dava antes ou coisas que eu dava pouco valor e, que hoje dou muito valor.

Quando a entrevistada relata que seu cotidiano ficou alterado, nisso estão implicadas inúmeras mudanças, dentre elas, conviver com as sequelas causadas pelo acidente. Frente a isso, Silva, Schlicknann e Faria (2002) abordam que a recuperação do estado de coma, ou ainda de uma enfermidade grave, pode também significar a convivência com sequelas e a aceitação de limites, mesmo não estando confortável com eles. Trabalhar com as emoções, frustrações, as perdas e tentar encontrar coerência sobre o que significou ser/estar doente, são algumas das metas que devem estar presentes no cuidado e auxilio para melhor aceitação da situação, pelo sujeito que a vivencia. É importante também reconhecer a natureza curativa de qualquer processo de doença, ou seja, reconhecer a doença enquanto oportunidade de mudança e redirecionamento do processo de ser e viver. Muitas pessoas necessitam de apoio e ajuda para reverem suas atitudes, crenças e valores e, ao mesmo tempo, buscarem novas prioridades em suas vidas. Exemplificando:

\begin{abstract}
O período de hospitalização foi um período que eu tive que ter muita paciência né? Porque foram 78 dias dentro de um hospital! Não é fácil tu ser uma pessoa ativa e acontecer de um dia pro outro tu "tá" em cima de uma cama, dependente de uma pessoa pra fazer tudo pra ti. No hospital ainda, não conseguia desempenhar nenhuma atividade de vida diária sozinha, então eu tinha dependência desde escovar meus dentes, pentear meu cabelo, tomar banho...
\end{abstract}

Outra situação muito relevante, frente às perdas e marcas (tanto físicas, quanto emocionais) foi à perda de amigas; fato, bastante comentado durante as entrevistas, que trouxe impacto para o cotidiano da sobrevivente.

Eu precisei de ajuda, porque eu perdi três amigas e colegas, foi então um recomeço de muita luta pra poder voltar a minha rotina. Acho que o maior desafio foi conviver com a ausência das gurias. 
Frente a essa situação, Silva et al. (2007) discorrem que a repercussão dessas perdas no indivíduo dependerá de seus fatores pessoais, sociais e formas de enfrentamento. É possível superar as perdas desde que o indivíduo conte com fatores que lhe permitam apoio, reflexão e tratamento. $\mathrm{O}$ ciclo de amizades e o vínculo familiar são formas de apoio capazes de transmitir ao indivíduo segurança emocional, mesmo quando se encontra exposto a situações traumáticas, como a morte de alguém. Desse modo, esse suporte esteve fragilizado uma vez que todo o grupo de amizades em que o sujeito da pesquisa estava inserido foi abalado, pois essas perdas foram muito significativas e abrangentes. Evidencia-se que a dor e a angústia pela perda das amizades, demandaram da sobrevivente momentos de ressignificação e de resiliência.

Nessa perspectiva, frente a todas essas modificações no cotidiano, as atividades de rotina também atuam como outra forma de dizer da condição humana, de apresentar um compromisso real com a existência, de promover trocas sociais, de romper com o isolamento dos sujeitos, de mostrar possibilidades, de dar conta de novas experimentações (CASTRO; LIMA; BRUNELO, 2001). Frente a isso, o sujeito do estudo relata:

Aos pouquinhos eu pude retomar algumas atividades de vida diária sozinha, as que eu conseguia fazer sozinha, eu me esforçava [...] pra conseguir fazer sozinha.

A vida cotidiana, sob vários aspectos, passa a ser heterogênea, sobretudo no que se refere ao conteúdo e à significação ou importância que o sujeito atribui a cada parte do cotidiano (HELLER, 2000). Ainda, as verdadeiras aprendizagens, como bem enfatizava Paulo Freire (1996), são aquelas em que as pessoas vão se transformando em sujeitos reais do processo, participando de uma maneira ativa de todas as suas etapas. Seguindo nesse pensamento a entrevistada coloca que:

Trago hoje, um amadurecimento, tive que enfrentar toda essa situação com muita força e fé. Força por que via quem eu amo e me ama sofrendo, por me ver daquele jeito e também, para seguir a vida. Fé por acreditar em Deus que tudo ficaria bem, por mais que o processo de recuperação fosse longo, mas que aos poucos conseguiria reverter a situação. Me vejo uma nova pessoa, com mais paciência, pé no chão, com os sentimentos mais aflorados, mais sensível, mais serena. Antes eu acordava e pensava que tudo não passava de um sonho. E no sonho, eu era amputada e tinha os 
braços queimados, onde todos me olhavam diferente e com pena, mas sempre achava que ao abrir os olhos, voltaria a ser como antes, com as duas pernas e igual as mulheres da mesma idade. Ao passar dos meses pude ver que não era uma perna ou uma queimadura que definiria uma pessoa, e sim, o crescimento, o caráter, o coração, os sentimentos e as dores que carrego. Hoje, estou aqui, diferente, mais madura e aprendendo todos os dias com tudo que mudou a minha vida a partir do dia 27 de janeiro de 2013.

As doenças interferem diretamente nos projetos existenciais das pessoas, exigindo uma ressignificação de suas vidas. Com isso, os episódios de doença levam à reflexões e questionamentos dos indivíduos no e com o meio em que se encontram. Desse modo, ressignificar é produzir sentidos para a experiência da doença (Alves, 1994 apud SELLI et al., 2008).

Diante das mudanças ocorridas e discutidas nesse item, os sobreviventes necessitaram de um cuidado integral em saúde, que potencializasse a ressignificação de sua vida. Isto é, através de uma equipe de profissionais que disponibilizasse de uma atenção qualificada às diversas demandas que a tragédia exigiu.

\section{Terapia Ocupacional e o Cuidado}

O cuidado é um elemento que compõe as práticas de saúde, não se reduzindo a instrumento de trabalho, caracteriza-se como um dispositivo que pode produzir subjetividade e ressignificação para as pessoas em situação de doença (SELLI et al., 2008).

Nesse contexto, Merhy (1998) elucida que o cuidado diz respeito à capacidade dos trabalhadores de saúde e cuidadores de considerar a dimensão subjetiva e existencial presente e operante na vida do sujeito e sua influência no processo de ressignificação. Assim, o cuidado não se esgota com a realização de técnicas e procedimentos profissionais terapêuticos objetivos. Ao contrário, possui um elemento subjetivo que remete para a dimensão humana. O cuidado penetra o universo da existência humana, avança para o espaço do sentido, para o qual a tecnologia não tem respostas. Sobre o cuidado e a humanização deste, a entrevistada relata:

A profissional TO, me auxiliou a ver a vida de um outro jeito, os atendimentos me ajudaram a ver que eu era capaz de fazer as coisas que eu fazia antes, me deram força de vontade para superar todos os obstáculos que eu tive, do 27 de janeiro pra frente, e os que eu vou ter ainda. 
A partir dessa situação e do relato sobre o cuidado, imerge-se no campo da Terapia Ocupacional, acionando ocorrências ligadas ao cuidado e práticas nesse contexto. Para isso, Castro (2005) aborda que no campo das práticas em Terapia Ocupacional no Brasil, os terapeutas ocupacionais - muitas vezes - encontram-se com questões singulares que nos transportam para questões não somente clínicas, mas questões do cotidiano e da organização das vidas que nos surpreendem e nos desafiam.

Para tanto, acompanhar as ações de sujeitos com histórias complexas nos remete a um campo de criatividade, de singularidades, de culturas diferentes, de heterogeneidades e, a isso, relaciona-se à construção do acesso às múltiplas informações de diferentes áreas, como por exemplo, da Reabilitação, da Saúde, da Educação, da Cultura, do Social e de outros campos do conhecimento.

Os profissionais terapeutas ocupacionais atuam nas disfunções que se manifestam em diferentes áreas da vida dos sujeitos e que por diversas razões foram impedidos de prosseguir formando sua própria história na multiplicidade de linhas narrativas proporcionadas pela experiência do viver. Nesse contexto, seguem excertos de falas da entrevistada:

[...] com o treino das atividades de vida diária, as adaptações e na parte das tecnologias assistivas que necessitava, eu consegui aos poucos voltar a realizar o que eu fazia antes do acontecido. Então, eu tinha bastante fadiga, devido à perda muscular e fraqueza, eu também tive vários problemas de visão e memória, também perdi a sensibilidade do pé esquerdo e, também, nos meus braços em razão das queimaduras. Mas, aos poucos com o treino das atividades de vida diária e também com a estimulação sensorial, foi quando eu comecei a voltar a ter meus movimentos e a sensibilidade novamente... O trabalho foi fundamental em todos os atendimentos que eu tive, porque a TO me fazia ver aquele corpo com sequelas, no caso, era de uma pessoa que passou pelo que passou e era uma pessoa forte que tinha que continuar, dar a volta por cima $[\ldots]$.

[...] então a importância da Terapia Ocupacional foi que eu voltasse a realizar as atividades de vida diária sozinha e com a independência que eu tinha antes [...] Desde poder me maquiar, de poder tentar me ver bonita, até de eu poder tomar um banho, sem perigo de cair. 
A Terapia Ocupacional trabalha com as atividades que possibilitam ao sujeito reconhecer-se e ser reconhecido pelos outros. O fazer e as atividades realizadas pelo indivíduo descrevem a história de vida de cada um. No entanto, é nesse resgate da história de cada sujeito, permeado pelas atividades, que se encontra o território, onde se descobrem interesses, capacidades e potencialidades que delineiam caminhos possíveis no campo das produções humanas, situação muito significativa quando se trata de ressignificação do cotidiano (CASTRO; LIMA; BRUNELLO, 2001).

Assim sendo, após o evento traumático, verifica-se dificuldades em atividades anteriormente realizadas de forma automática, sem a percepção do quão complexas podem ser para quem apresenta dificuldades momentâneas ou não. Dessa forma, Mastropietro, Santos e Oliveira (2006), trazem à baila que a Terapia Ocupacional tem uma posição privilegiada ao poder colaborar para a elaboração crítica e ressignificação do cotidiano do sujeito. Pois, na Terapia Ocupacional também é necessário garantir a humanização no tratamento e recriar o cotidiano. Além disso, é importante auxiliar o sujeito na realização das tarefas do dia a dia, oferecendo um suporte no enfrentamento da situação criada pela patologia e ajudando na reconstrução do cotidiano (ALENCAR; TERADA, 2012).

Seguindo com essa abordagem, autores comentam que os sujeitos inseridos em práticas e intervenções em Terapia Ocupacional, em geral, vivenciaram uma ruptura na sua vida cotidiana. Portanto, na atenção a essas pessoas é preciso reconhecer o que mudou, as ocupações que se tornaram improváveis, ou que precisam de adaptações para sua realização, mesmo que muitas vezes isso represente um momento de luto pelo que se perdeu. O terapeuta ocupacional busca, com o sujeito, maneiras para ele não se fechar na impossibilidade, resgatar sua história de vida, a história de suas ocupações, descobrindo um caminho de continuidade entre o passado e o presente e também de continuidade com o futuro, abrindo espaço para o novo, para a redescoberta de outras e novas ocupações (SALLES, MATSUKURA, 2013).

Nesse sentido, Anversa e Borges (2016) comentam que o terapeuta deve estar disposto a vincular-se e estabelecer com o cliente uma relação de confiança e parceria em sua prática, a fim de alcançar os objetivos do cuidado. Dessa maneira, nota-se o papel da Terapia Ocupacional na ressignificação 
do cotidiano, com a intenção de transformar o sujeito, ressignificar sua vida, seus conceitos, e proporcionar qualidade de vida.

\section{CONSIDERAÇÕES FINAIS}

De Retomar uma situação de grande comoção, como o "Caso Boate Kiss", não é uma tarefa simples, muito menos fácil, por ser ainda, algo muito vivo e em processo de elaboração por todos que de alguma forma estiveram envolvidos com a situação. Porém, muito do que resgatou-se nesse estudo pode vir a contribuir para pessoas que encontram-se em situações semelhantes e, especialmente, para os profissionais que acompanham casos próximos ao que fora descrito. Assim, buscou-se mostrar, no decorrer desta pesquisa, como está se processando a ressignificação do cotidiano por uma sobrevivente do incêndio na boate Kiss, dando voz a quem sofreu "na pele" cada consequência do que o referido acidente gerou.

A situação vivenciada possuiu, e ainda apresenta, grande repercussão e comoção, principalmente, para a população da cidade em que o fato ocorreu, trazendo sensibilidade, solidariedade e amadurecimento. Nesse contexto, estão inseridos os profissionais de saúde que auxiliaram no processo de reabilitação e busca de ressignificação dos sujeitos envolvidos.

O desenvolvimento deste estudo possibilitou deslocar o olhar das questões tecnicistas, para compreender o real impacto da tragédia no cotidiano do caso em questão, abordando não só as consequências geradas pelo incêndio, como também, os modos de enfrentamento e continuidade desenvolvidos pelo sujeito, para retomar suas atividades cotidianas.

O cotidiano é singular, contínuo e complexo. Todavia, muitas vezes, sua importância só é observada quando acometido por situações de rompimento. Portanto, falar de perda significa, falar de vínculo que se rompe, de uma parte de si que é perdida, sendo preciso a ressignificação, comentada neste estudo, e o investimento em novas relações e experiências; conforme necessitou o sujeito participante, que teve perdas concretas e reais, como a morte de pessoas próximas e alterações e marcas em seu corpo, dentre outras.

A sociedade, infelizmente, pode estar suscetível a situações próximas ao caso abordado. Por isso, é relevante que existam novas pesquisas e estudos sobre a temática, para que não haja um despreparo, principalmente, por parte dos profissionais (enfermeiros, terapeutas ocupacionais, fisiotera- 
peutas, médicos...) ao enfrentamento dessas situações. Percebeu-se que a Terapia Ocupacional tem importante papel diante da complexidade do cotidiano e das vivências envolvidas neste evento, bem como na (re) adaptação de indivíduos a sua rotina.

\section{REFERÊNCIAS}

ALENCAR, M. C. B.; TEREDA, T. M. O afastamento do trabalho por afecções lombares: repercussões no cotidiano de vida dos sujeitos. Revista de Terapia Ocupacional da USP, São Paulo, v. 23, n. 1, p. 44-51, 2012.

ANVERSA, A. C.; BORGES, J. M. Prática de estágio em terapia ocupacional na comunidade. Cadernos de Terapia Ocupacional, São Carlos, v. 24, n. 4, p. 821-826, 2016.

ASSIS. C. T. S., SÓRIA. D. A. C., ASSIS. M. R. A queimadura como ato de violência física contra a mulher: revisão de literatura. Rev Bras Queimaduras, v. 11, n.4, p. 254-258, 2012.

BARDIN, L. Análise de conteúdo. Lisboa: Edições 70; 2006.

BESSA, J. K. M.; SILVA, T. E. O.; ROSA, S. M. Mulheres vítimas de queimaduras nas atividades da vida diária. Cadernos de Terapia Ocupacional, São Carlos, v19, n.2, p 153-164, 2011.

CARRETEIRO T. C. Corpo e contemporaneidade. Psicologia em Revista, Belo Horizonte, V. 11, n. 17, p. 62-76, 2005.

CASTRO, E. D. de. Inscrições da relação terapeuta-paciente no campo da terapia ocupacional. Rev. Ter. Ocup. Univ. São Paulo, v. 16, n. 1, p. 14-21, 2005.

CASTRO, E. D.; LIMA, E. M. F. A.; BRUNELLO, A. I. B. Atividades humanas e Terapia ocupacional. In: DE CARLO, M. M. R. P.; BARTALOTTI, C. C. (Org.). Terapia Ocupacional no Brasil: Fundamentos e perspectivas. São Paulo: Plexus, 2001, p. 41-59.

FINGER, J.A.O. Terapia Ocupacional. $1^{\text {a }}$ ed. São Paulo. Sarvier; 1986.

FRANCISCO, B. Terapia Ocupacional. 2 ${ }^{\mathrm{a}}$ Ed. Campinas. Papirus; 2001.

FREIRE, P. Pedagogia da autonomia: saberes necessários à prática educativa. São Paulo: Paz e Terra, 1996 (Coleção Leitura).

GALHEIGO, S.M. O cotidiano na terapia ocupacional: cultura, subjetividade e contexto histórico-social. Rev Ter. Ocup. Univ. São Paulo, São Paulo, v.14, n.3, p. 104-109, 2003.

GOFFMAN, E. Estigma - notas sobre a manipulação da identidade deteriorada. 4a ed. Rio de Janeiro: LTC; 1988

GUERRERO, G. P. et al. Relação entre espiritualidade e câncer: perspectiva do paciente. Revista Brasileira de Enfermagem, São Paulo, v.64, n.1, p.53-59, 2010.

HAROLD, G. KOENIG, M.D. Espiritualidade no cuidado com o paciente: Por que, como, quando e o que. Montenegro: Cataventos, 2005.

HELLER, A. O cotidiano e a história. São Paulo: Paz e Terra, 2000, 6a ed. 
MASTROPIETRO, A. P.; SANTOS, M. A.; OLIVEIRA, E. A. Sobreviventes do transplante de medula óssea: construção do cotidiano. Revista de Terapia Ocupacional da Universidade de São Paulo, São Paulo, v.17, n.2, p. 62-71, 2006.

MERHY, E. E. A perda da dimensão cuidadora na produção da saúde: uma discussão do modelo assistencial e da intervenção no seu modo de trabalhar a assistência. In: Campos CR, Malta DC, Reis AT, Santos AF, Merhy EE, organizadores. Sistema Único de Saúde em Belo Horizonte: reescrevendo o público. São Paulo: Xamã; 1998. p.103-20.

MINAYO, M.C.S. Pesquisa social: teoria, método e criatividade. Petrópolis. Vozes; 1994.

PAIVA, L.L.; GOELLNER, S.V. Reinventing life: a qualitative study on the cultural meanings attributed by amputees to body reconstruction through implantation of prosthetics. Interface - Comunic., Saúde, Educ., v.12, n.26, p.485-97, 2008.

PERES, J. F. P.; MERCANTE, J. P. P.; NASELLO. A. G. Promovendo resiliência em vítimas de trauma psicológico. Neurociências Rev Psiquiatria, v.27, n.2, p.131-138, 2005.

PESSINI, L. A Espiritualidade interpretada pelas ciências e pela saúde. O mundo da saúde. São Paulo, v.31, n.2, p. 187-195, 2007.

RIO GRANDE DO SUL. Secretaria de Segurança Pública. Polícia Civil - $1^{\text {a }}$ Delegacia de Polícia de Santa Maria - RS. Inquérito Policial n 94/2013/150501. Disponível em: http://estaticogl.globo.com/2013/03/22/relatorio_kiss_definitivo.pdf. Acesso em 02 de agosto de 2015, ás 13h10min.

RORATTO, G. Incêndio em boate no RS mata mais de 240 na maior tragédia em 50 anos. G1 - Globo, São Paulo, SP, 28 jan. 2013. Disponível em: <http://g1.globo.com/rs/rio-grande-do-sul/tragedia-incendio-boate-santa-maria/platb/> Acesso em: 31 de julho de 2015.

SALLES, M. M., MATSUKURA, T. S. Estudo de revisão sistemática sobre o uso do conceito de cotidiano no campo da terapia ocupacional no Brasil. Cadernos de Terapia Ocupacional da UFSCar, São Carlos, v.21, n.2, p. 265-273, 2013.

SELLI, L. et al. El cuidado médico en la resignificación de la vida ante la enfermedad. $O$ Mundo da Saúde São Paulo: 2008: jan/mar 32(1):85-90

SILVA, A.L.; SCHLICKNANN, G.C.; FARIA, J.G. O coma e seu impacto no processo de ser e viver: implicações para o cuidado de enfermagem. Rev. gaúcha Enferm., Porto Alegre, v. 23, n. 2, p. 81-107, 2002.

SILVA, C.A. ; CARVALHO, L. S. ; SANTOS, A. C. P. O. ; MENEZES, M.R. Vivendo após a morte de amigos: história oral de idosos. Texto Contexto Enferm, Florianópolis, v.16, n.1, p. 97-104, 2007. 


\section{Juliana Maia Borges}

Terapeuta Ocupacional. Mestre em Reabilitação e Inclusão. Centro Universitário Metodista - IPA, Porto Alegre, RS, Brasil.

E-mail: jumaiaborges@yahoo.com.br

\section{Andreisi Carbone Anversa}

Terapeuta Ocupacional. Mestre em Distúrbios da Comunicação Humana. Universidade Federal de Santa Maria - UFSM, Santa Maria, RS, Brasil.

E-mail: andreisianversa@hotmail.com

\section{Marlis Morosini Polidori}

Educadora Física. Doutora em Ciências da Educação pela Universidade do Porto, Portugal. Docente do Programa de Mestrado Profissional em Reabilitação e Inclusão do Centro Universitário Metodista - IPA, Porto Alegre, RS, Brasil.

Email: marlispolidori@gmail.com 